\title{
Beyond ePortfolios \\ Creating, Exploiting, and Archiving Activity Traces, Learning Outcomes, and Learning Analytics as Personal Shareable Online Spaces
}

\author{
D. Gillet, M.J. Rodríguez-Triana, A. Holzer, \\ A. Vozniuk, J.C. Farah \\ School of Engineering \\ Swiss Federal Institute of Technology (EPFL) \\ Lausanne, Switzerland \\ denis.gillet@epfl.ch
}

\author{
R. Matsuba \\ Research Center for Instructional Systems \\ Kumamoto University \\ Kumamoto, Japan \\ matsuba@kumamoto-u.ac.jp
}

\begin{abstract}
The concept of an ePortfolio was introduced in 1999 as an electronic learning record and further developed to overcome the limitation of learning management systems lacking persistent storage for learning artifacts. Nowadays, educational platforms have evolved towards personal learning environments and social media platforms, enabling the creation, exploitation and archiving of activity traces, learning outcomes, and learning analytics thanks to built-in export and sharing features. This paper presents the design and implementation of archiving and sharing services in Graasp, a general-purpose learning platform. These features enable implementing Graasp as an ePortfolio platform, allowing students to archive learning artifacts as evidence of competences and activity traces for analytics-driven self-assessment. Additionally, we discuss user requirements for designing such general ePortfolio services elicited from the analysis of functionalities of the Mahara popular ePortfolio platform and from a participatory design session with expert users of Graasp.
\end{abstract}

Keywords-Engineering Education; Learning Environment; Social Media; ePortfolio; Personal Learning

\section{INTRODUCTION}

Historically, the storage of learning artifacts on learning management systems and their access by students was bounded in time $[2,3]$, usually by the duration of the class. After a class was finished, artifacts were deleted or student access was revoked. To address this issue and support longterm access to learning artifacts by the students, ePortfolios were conceived [1]. Nowadays, educational platforms have evolved towards personal learning environments (PLEs) and social media platforms $[4,10]$, enabling the creation, exploitation and archiving of activity traces, learning outcomes (such as digital content, data, or discussions), and learning analytics [5] thanks to built-in export and sharing features. Such features enable students to store their digital learning artifacts together with the resources provided by the teacher(s) as archive files, PDF documents, eBooks, or shareable online spaces that can be considered as rich open educational resources [6] and evidence of goal achievement and competence acquisition.

This paper describes the design and implementation of versatile archiving and sharing services for self-assessment and competence management dedicated to science and engineering education, as well as to teacher professional development. Such services are implemented in Graasp ${ }^{1}$, an educational social media platform initially designed as a solution to create and exploit personal learning environments and open educational resources, but later extended to match features required by ePortfolios.

Section II presents the technological context in which the design of general purpose educational services and platforms are developed. Section III details the methodological approach implemented to carry out participatory design with key digital education stakeholders and elicit user requirements. Section IV provides a comparative study between a general purpose educational platform and a widely used ePortfolio system. Section $\mathrm{V}$ details the outcome of a participatory design session carried out with advanced users of educational platforms to understand their needs in terms of archiving features and ePortfolio services. Section VI summarizes the requirements elicited in the previous sections and Section VII discusses the implementation of the core required features in Graasp. In Section VIII, we describe a use case based on the current version of Graasp exploited to support both learning and competence management in an instructional design class, before concluding in Section IX.

\section{TECHNOLOGICAL CONTEXT}

Graasp is an open access educational social media platform developed in the framework of three successive European initiatives dedicated to online personal and inquiry learning $[7,10]$. In addition to enabling the creation of personal learning spaces supporting individual and group work, it allows the creation and exploitation of inquiry learning spaces (ILS), as well as their free publication and distribution through the Go-Lab repository ${ }^{2}$.

Fig. 1 shows a student view of a sample ILS called $M y$ $I L S$. The ILS tabs contain activities to be carried out as part of inquiry learning phases and provide the necessary online resources, such as documents, embedded web pages, YouTube

\footnotetext{
${ }^{1}$ Graasp: http://graasp.eu

${ }^{2}$ Go-Lab repository (Golabz): http://golabz.eu
} 
videos, web apps, and virtual or remote labs. The dashboard tab can integrate personalized learning analytics apps, such as one displaying a student's progress (Fig. 2) compared to other peers in the class [9].

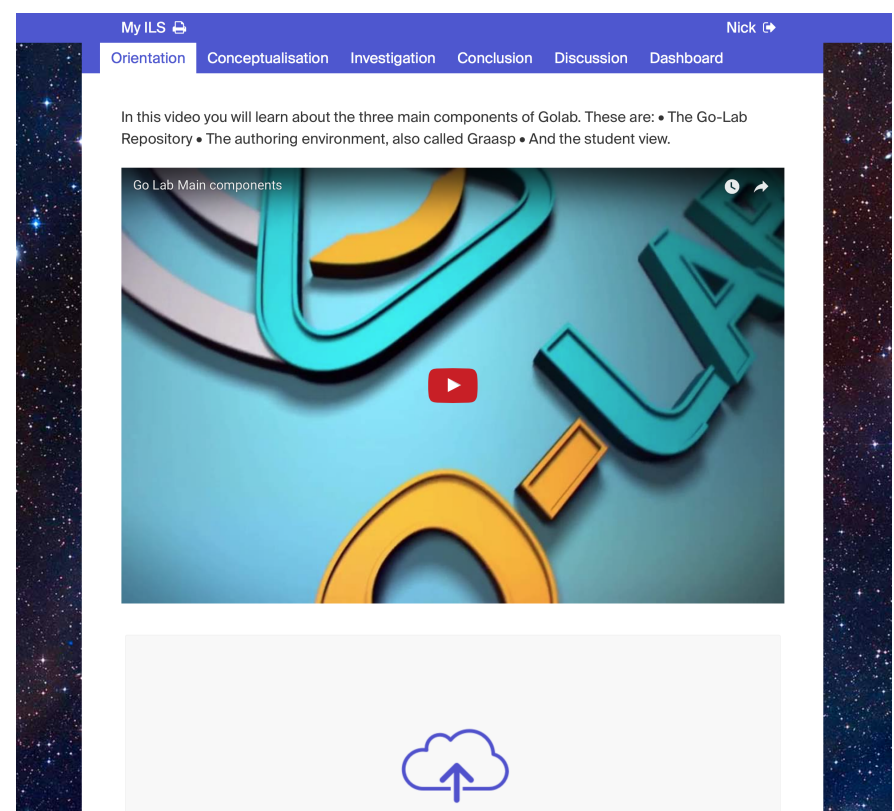

Fig. 1. An inquiry learning space called My ILS with tabs providing resources to carry out various inquiry learning activities and integrating a learning analytics dashboard. The selected tab is the Orientation phase that includes an embedded YouTube video and a web app enabling the student to add personal documents through drag-and-drop (cloud icon).

Students do not need to sign up or sign in to exploit an ILS. Once they have received the ILS's secret URL to the student view from their teacher, they can access it by providing an individual nickname. This schema preserves students privacy while enabling students to store and identify their learning outcomes and activity traces.

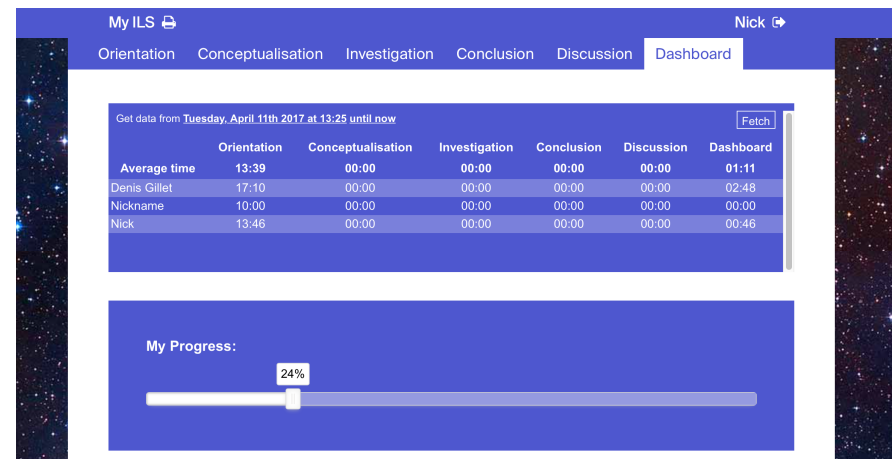

Fig. 2. The Dashboard tab of the ILS introduced in Fig. 1 integrates a web app showing how long students have spent in the various inquiry learning phases and a web app enabling the students to self-assess their current progress level.

\section{METHODOLOGICAL APPROACH}

For the elicitation of requirements for an ePortfolio system, we followed two complementary approaches. First, we carried out a comparative study between Graasp and Mahara - a popular tool for ePortfolio management [8]. The purpose of this study was to understand how the current capabilities of Graasp compare with Mahara and to identify directions for improvement within Graasp. Additionally, we organized a participatory design session with 24 teachers in July 2017. These teachers were proficient users of Graasp and the Go-Lab repository. By involving them in the design process, our goal was to learn how useful they considered ePortfolio services and archiving features in Graasp. Furthermore, we aimed to gather feedback on what data should be included in these ePortfolios and archives, as well as their preferred export formats.

\section{COMPARATIVE STUDY}

In this section, we discuss our study comparing Graasp and Mahara based on the minimal set of features required by an ePortfolio system as listed in [11]. These features are the following:

- digital collection of artifacts and reflections;

- representation of an individual's learning and achievements;

- $\quad$ set of items to be shared with others.

We selected Mahara as a representative example of ePortfolios because of its large and increasing worldwide user base. This adoption is due to its easy installation, good operability, and the fact that it is customizable with plug-in modules. In Table 1, we present a summary of the comparison.

TABLE I. COMPARISON OF FEATURES OFFERED BY THE GRAASP AND MAHARA PLATFORMS.

\begin{tabular}{|c|c|c|c|}
\hline \multicolumn{2}{|c|}{ Activities } & \multicolumn{2}{|c|}{ Platforms } \\
\hline Learner & Instructor & Graasp & Mahara \\
\hline $\begin{array}{l}\text { Goal } \\
\text { Management }\end{array}$ & & Profile & $\begin{array}{l}\text { Resume, Profile, } \\
\text { Plan, } \\
\text { SmartEvidence }\end{array}$ \\
\hline $\begin{array}{l}\text { Connection / } \\
\text { Sharing }\end{array}$ & $\begin{array}{l}\text { Summative } \\
\text { Evaluation }\end{array}$ & $\begin{array}{l}\text { Discussions \& } \\
\text { Documents }\end{array}$ & $\begin{array}{l}\text { Collection, Page, } \\
\text { SmartEvidence }\end{array}$ \\
\hline $\begin{array}{l}\text { Reflection } \dagger \\
\text { / Selection }\end{array}$ & & $\begin{array}{l}\text { Documents, } \\
\text { Files }\end{array}$ & Page, Note \\
\hline $\begin{array}{l}\text { Selection / } \\
\text { Reflection: }\end{array}$ & $\begin{array}{l}\text { Formative } \\
\text { Evaluation }\end{array}$ & $\begin{array}{l}\text { Documents, } \\
\text { Files }\end{array}$ & Page, Note \\
\hline Collection & & $\begin{array}{l}\text { Documents, } \\
\text { Files, Links, } \\
\text { Apps }\end{array}$ & $\begin{array}{l}\text { File, Journal, Note, } \\
\text { Images and Video, } \\
\text { External Content }\end{array}$ \\
\hline
\end{tabular}

$\uparrow$ Retrospective reflection for integration of knowledge.

+ Immediate reflection for formative evaluation of learning.

The two platforms integrate the required set of features listed above. Nevertheless, there are implementation differences regarding the collection of artifacts. Mahara includes various ways to collect learning artifacts and especially common multimedia documents. On the other hand, and in addition to collecting multimedia documents, Graasp enables the aggregation of external web apps and embedded web pages. The SmartEvidence feature of Mahara is a competency-visualizing tool in which the competencies acquired by students through their learning activities are 
associated with pieces of evidence. There is currently no such a feature in Graasp. On the Graasp side, the main advantage is the flexibility to personalize the platform through apps or embedded pages that can be easily integrated. These integrations enable the display of learning achievements acquired in other platforms. As nowadays students can use a multitude of learning platforms online, Graasp's ability to integrate external resources allows it to become the personal repository for a broad learning ecosystem, where students can compile knowledge acquired in both formal and informal learning settings and environments.

\section{PARTICIPATORY DESIGN}

We organized a participatory design session with 24 expert teachers in July 2017. In this session, teachers reflected on how they envisioned the archiving of ILSs and ePortfolio services to be integrated into Graasp.

Archiving for teachers. Out of 24 teachers, 21 (87.5\%) considered that keeping an archive was relevant for their own practice, 1 (4.16\%) was not sure, and $2(8.33 \%)$ did not answer. By decreasing number of votes, the main reasons motivating teachers to keep an archive of their ILSs were (1) assessment purposes (as evidence of the student's work and their progress), (2) compiling and having access to the material generated by the teachers, (3) re-usability (including reviewing and redesigning), (4) sharing with other peers, (5) self-reflection, and (6) research.

Regarding the content that such archive should include, teachers considered that it should contain evidence not only about the content $(24,100 \%)$ but also about the activity (23, $95.83 \%$ ). Table 2 shows the teachers' preferences in terms of archiving solutions. It should be noted that several solutions could be chosen by the teachers at the same time. The main options were to keep the archives in Graasp (83.33\%), in their own computer $(62.5 \%)$ or as a PDF $(62.5 \%)$. Regarding the certification, most of the teachers $(23,95.83 \%)$ were interested in getting a certification from the platform showing that the ILSs were produced by them.

Student ePortfolio. Out of 24 teachers, 21 (87.5\%) stated that it would be useful for students to add their ILSs to their ePortfolios, and $3(12.5 \%)$ were not sure. In order to better address the student needs, we asked the teachers what kind of information should be included in an ePortfolio. On this regard, 21 teachers $(87.5 \%)$ agreed on the need for combining evidence about the learning outcomes as well as the learning process. Besides, other data sources were considered as relevant in an ePorfolio, e.g., the student self-assessment or the feedback provided by peers or teachers. Indeed, 22 teachers $(91.67 \%)$ were willing to certify the authenticity of the work done by the students (the other 2 were not sure).

In terms of how ILSs could be exported, the preferences diverge from the ones chosen for teacher archiving. As it is shown in Table 2, the most voted options were PDF files (15 teachers, 62.5\%), in Graasp (14 teachers, 58.33\%), and ePub/eBook (10 teachers, 41.67\%). Interestingly, as for teacher archiving, despite the PDF format appearing among the main options, it is not aligned by default with the possibility of including raw evidence about the learning process. Nevertheless, this data could be aggregated and analyzed by ad-hoc analytics apps, which can also provide some guidelines for interpretation and reflection.

TABLE II. TEACHER INTEREST IN THE DIFFERENT ARCHIVING AND EPORTFOLIO STRATEGIES.

\begin{tabular}{|l|r|r|}
\hline \multicolumn{1}{|c|}{ Archiving / ePortfolio Strategies } & \multicolumn{1}{c|}{ For Teachers } & \multicolumn{1}{c|}{ For Students } \\
\hline Printed Copy (Paper-Based) & $4(16.66 \%)$ & $5(20.83 \%)$ \\
\hline PDF File & $15(62.50 \%)$ & $15(62.50 \%)$ \\
\hline ePub / eBook File & $7(29.16 \%)$ & $10(41.67 \%)$ \\
\hline In Graasp & $20(83.33 \%)$ & $14(58.33 \%)$ \\
\hline In User's Computer & $15(62.50 \%)$ & $4(16.66 \%)$ \\
\hline $\begin{array}{l}\text { In Another Server (e.g., In User's } \\
\text { School Network) }\end{array}$ & $5(20.83 \%)$ & $7(29.16 \%)$ \\
\hline Google Drive & $1(4.16 \%)$ & $1(4.16 \%)$ \\
\hline
\end{tabular}

\section{ELICITED REQUIREMENTS}

Based on the comparative study and the participatory design presented in Sections IV and $\mathrm{V}$, respectively, we formulate two additional requirements for ePortfolio systems:

- $\quad$ storage of activity traces together with artifacts;

- proper management of user identities.

Activity traces storage. Most of the ePortfolio systems focus on collecting artifacts representing the final product of a learner's work. In addition, it has an important role as a workplace of learning. We argue that for analytical and reflection reasons, the activities performed while working on the artifacts are also important. Having access to the activities as part of an ePortfolio can enable using learning analytics and personalization tools tailored to the learning style of a particular student. For instance, based on the traces stored as part of an ePortfolio, the system can recommend learning activities with short duration matching previous successful experiences of the learner. Moreover, such activity traces can serve as a data source for teacher dashboards assisting the teacher in the examination of an ePortfolio for a particular student.

A challenge arises when persisting traces of interactions that happened as part of collaborative activities. One example could be a collaborative report writing (e.g., in a Google Doc or a wiki page), where storing activity traces of a single user (e.g., characters written by the user) will provide an incomplete picture regarding the activities that led to the creation of the artifact. On the other hand, storing traces of all users participating in collaborative activities can raise privacy concerns related to the ownership of the traces. An ePortfolio system should have a clear policy and inform users how their traces are managed.

User identity management. Collection and storage of activity traces are strongly coupled with user identity management. As an example, when students interact in Graasp in the student view (such as the one shown in Fig. 1), they use nicknames to represent their identity. Such nicknames aim to protect user privacy during the class' online activities. At the 
same time, when exporting artifacts and traces as part of an ePortfolio, it is necessary for the learner to make a link with a real identity to be able to present the artifacts as proof of their work. Such identity linking mechanisms are required to be implemented by ePortfolio systems, especially given the fact that currently learning activities often happen across several learning environments, each having different user identities.

The following additional challenges must be also taken into account when implementing ePortfolio features:

- Compliance: How can we guarantee compliance with legal frameworks such as the EU General Data Protection Regulation ${ }^{3}$ ? Can underage students create accounts on open educational platforms?

- Access: Who (teachers, parents, hosting institutions, etc.) has temporary or permanent access to the content created by students in the context of a class? Who manages access permissions?

- Ownership: How do we store the learning outcomes of collaborative learning activities? How are rights transferred when students reach adulthood?

- Interoperability: How do we retrieve and store online content and apps integrated in ILSs while complying with their various license schemes?

- Identification: How can we extend the anonymous exploitation scheme based on contextual nicknames to support sustainable access for users with permanent credentials (independent from institutional identity)?

- Durability: How do we guarantee the durability of information?

\section{IMPLEMENTATION OF EXPORT AND ARCHIVING FEATURES}

To enable reflection and lifelong competence management in a digital society where the lifespan of cloud or legacy platforms is unpredictable, the most important feature to enable ePortfolio services is to ensure easy export and archiving in standard formats. This section describes the envisioned design and seamless integration of such features in Graasp towards its extension for exploitation also as an ePortfolio. For teachers, being able to export and archive the outcomes and traces of activities with their students is a way to reflect on and improve their teaching practices and professional achievements. For students, being able to export and archive the outcomes and traces of their activities is a way to support self-assessment of their learning practices and enable competence management.

The current export feature available in Graasp relies on printing the full content of ILSs as a PNG image or a PDF file (see in Fig. 1 the small printer icon located next to the name of the ILS on the top). We are currently implementing two further export features: Graasp Copy and Zip Archive.

Graasp Copy. This functionality will enable students to obtain their own personal copy of the ILS in Graasp. This will require students to provide Graasp credentials so that Graasp can verify their identity. Fig. 3 shows the Graasp copy of an

\footnotetext{
${ }^{3}$ http://www.eugdpr.org
}

ILS as it has been created by the teacher (with subspaces depicted as folders and exploited to collect and aggregate cloud resources supporting the various phases). Note that in the teacher space, the Vault subspace contains the learning outcome of all students. The individual student copies should only contain personal production and traces. The personal collection of ILSs stored in Graasp can be considered as an ePortfolio, since it is persistent and can be freely shared by its owner(s) for temporary or permanent consultation or exploitation. It should be emphasized that the copy of the space should include not only content such as documents and images, but also, discussions, activity traces and analytics. These are exported and kept for later use by the students, even in the case the teacher(s) decide to delete the original space. Fig. 2 shows an example of a dashboard of the previouslyintroduced ILS integrating two learning analytics apps.

Zip Archive. Finally, as it is already the case for registered Graasp users, it will be possible for students to archive an ILS in a zip format directly from the student view without the need to provide credentials. In the zip, spaces become folders and all content and descriptions are saved as files. Possibly, this folder can be uploaded to Graasp, where it recreates a fully working space. It should be noted that the same restrictions regarding personal traces in Graasp Copy apply here.

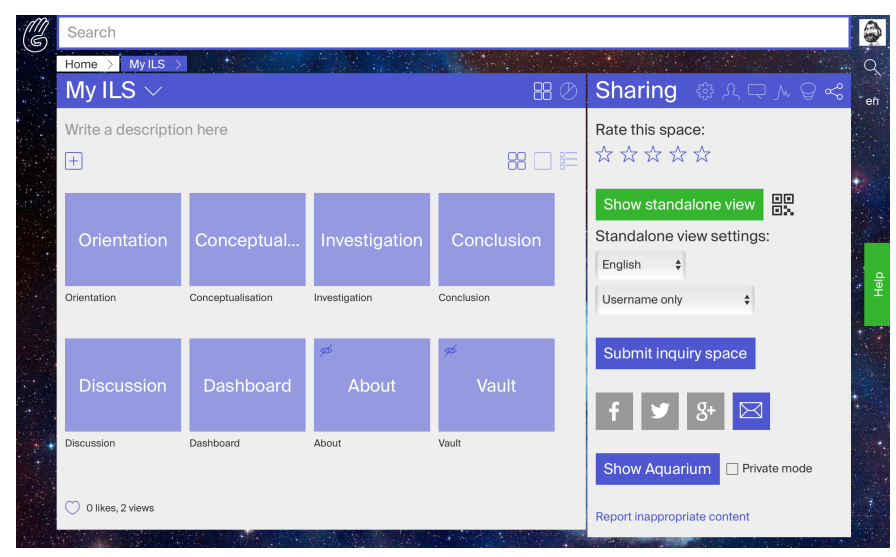

Fig. 3. The editable and sharable view of the My ILS inquiry learning space as created by the teacher and archived by the students.

\section{USE CASE}

As shown above, Graasp is a learning environment that enables students not only to achieve their goals in formal and/or informal learning, but also to manage their learning outcomes and traces. Hence, Kumamoto University has designed a higher education course for graduate students in instructional design aiming at supporting the development of ePortfolio literacy by using a learning platform integrating ePortfolio services. It will be extended later for undergraduate students for the development of more general digital literacy. The scenario of the graduate course and the way the Graasp platform will be exploited are detailed below.

The course will be organized in 6 modules of one day each. Students will be requested to reflect on their own learning activities. In this task, students will collect learning outcomes and describe their learning experience.

To guide the activity, students will first be asked to 
summarize what they have learned, and provide adequate artifacts or articles constituting evidence of their learning, justifying the decision and highlighting the relevance of the evidence provided. This simultaneously provides scaffolding for reflection and connection. As it is shown in Table 1, students can include documents, files, links, and apps in Graasp. We expect links or apps to be particularly useful, because students can easily aggregate outcomes available as artifacts on a learning management system or on Internet cloud services.

The reflection phase is about figuring out own learning outcomes through self-discovery. During the activity the students need to carefully consider the significance and the importance of their own learning experiences using selected data and notes accumulated in the previous phase. The reflection assignments will include showing the student outcomes (as a narrative story) in a context of this learning experience with evidence, and explaining how and why the student identified and/or produced artifacts as evidence.

Students will try to explain key learning dimensions, such as what they learn, how they learn, difficulties, and insufficient understanding of their learning experiences. Then they will be asked to consider what knowledge is acquired in which learning context or through which modality.

The continuing phase of reflection and connection is part of social learning. Hence, the students will be asked to provide a story (narrative) about their achievements in the perspective of collaborative learning. The reflection and connection assignments will entail publishing the learning achievements (narrative) in the perspective of collaborative learning (class, institution, company, etc.), and providing actions and approaches necessary to achieve the student's future goals.

Learning how to clearly convey their own understanding to others is an important task for students supported by reflecting on their own achievements. This also supports the decisionmaking process for defining learning goals, strategies and actions. The Graasp personalized structure with spaces and subspaces dedicated to selected activities, as well as the associated aggregated resources, can be seen as scaffolds to support this process and the acquisition of the associated competencies.

The course described here will be adapted and offered in different contexts, including science education at school and teacher training at university. The latter is about documenting teaching activities, exchanging opinions, and sharing best practices with colleagues using ePortfolio services.

\section{CONCLUSIONS}

This paper discusses how a general purpose educational platform, i.e. Graasp, can be exploited and possibly extended to offer ePortfolio services. We have presented archiving and sharing services in Graasp with the aim of supporting student self-assessment and competence management, as well as for teacher professional development. Offering a general-purpose educational platform including ePortfolio features enables learners to use a single platform for both their learning activities and the exploitation of their outcomes and traces for self-reflection and competence management.

The implementation of these services has highlighted a number of data management challenges regarding compliance, access, ownership, interoperability, identification, and durability. In future work, we aim to present solutions addressing these challenges, including the exploitation of blockchain technologies for the storage and the verification of learning outcomes, activity traces and other elements stored in ePortfolios.

\section{ACKNOWLEDGMENTS}

This work was partially funded by the European Union in the context of the Go-Lab Integrated Project and the Next-Lab Innovation Action. The latter has received funding from the European Union's Horizon 2020 Research and Innovation Program under Grant Agreement no. 731685. This publication reflects only the authors' view and the European Commission is not responsible for any use that may be made of the information it contains.

\section{REFERENCES}

[1] K. Barker, "The Electronic Learning Record: Assessment and Management of Skills and Knowledge", FuturEd, Literacy BC and the National Literacy Secretariat, Vancouver, Canada, 1999.

[2] J.A. Macías, "Enhancing Project-Based Learning in Software Engineering Lab Teaching Through an E-Portfolio Approach", IEEE Transactions on Education, Vol. 55, No. 4, 2012, pp. 502-507.

[3] R. Matsuba, S.-I., M. Miyazaki, T. Kita, J. Nemoto, K. Suzuki, H. Nakano, "An Implementation of a Learning Portfolio", Proceedings of the 10th International ePortfolio and Identity Conference (ePIC), 2012, pp. 186-190.

[4] D. Gillet, A. Vozniuk, M.J. Rodríguez-Triana, and A. Holzer, "Agile, Versatile, and Comprehensive Social Media Platform for Creating, Sharing, Exploiting, and Archiving Personal Learning Spaces, Artifacts, and Traces", Proceedings of the World Engineering Education Forum, 2016, pp. 1-12.

[5] B. Schwendimann, M.J. Rodríguez-Triana, A. Vozniuk, L.P. Prieto, M. Boroujeni, A. Holzer, D. Gillet, and P. Dillenbourg, "Perceiving learning at a glance: A systematic literature review of learning dashboard research", IEEE Transactions on Learning Technologies, Vol. 10, No. 1, 2017, pp. 30-41.

[6] M.J. Rodríguez-Triana, and al., "Rich Open Educational Resources for Personal and Inquiry Learning Agile Creation, Sharing and Reuse in Educational Social Media Platforms", Proceedings of the International Conference on Web \& Open Access to Learning, 2014, pp. 1-6.

[7] T. de Jong, S. Sotiriou, and D. Gillet, "Innovations in STEM education: The Go-Lab federation of online labs", J. Smart Learning Environments, Vol. 1, No. 3, 2014, pp. 1-16.

[8] Brown, M., Anderson, B., Simpson, M., \& Suddaby, G. Showcasing Mahara: A new open source eportfolio. Proceedings of ASCILITE Singapore, 2007, 82-84.

[9] A. Vozniuk, M. J. Rodríguez-Triana, A. C. Holzer, S. Govaerts and D. Sandoz et al. Contextual Learning Analytics Apps to Create Awareness in Blended Inquiry Learning. Proceedings of the 14th International Conference on Information Technology Based Higher Education and Training, 2015, pp. 1-5.

[10] A. Vozniuk, D. Gillet (Dir.). "Enhancing Social Media Platforms for Educational and Humanitarian Knowledge Sharing: Analytics, Privacy, Discovery, and Delivery Aspects." PhD Thesis $\mathrm{n}^{\circ}$ 7495, EPFL, Lausanne, 2017.

[11] T.P. Light, H.L. Chen, J.C. Ittelson. Documenting learning with ePortfolios: A guide for college instructors. John Wiley \& Sons, 2012. 